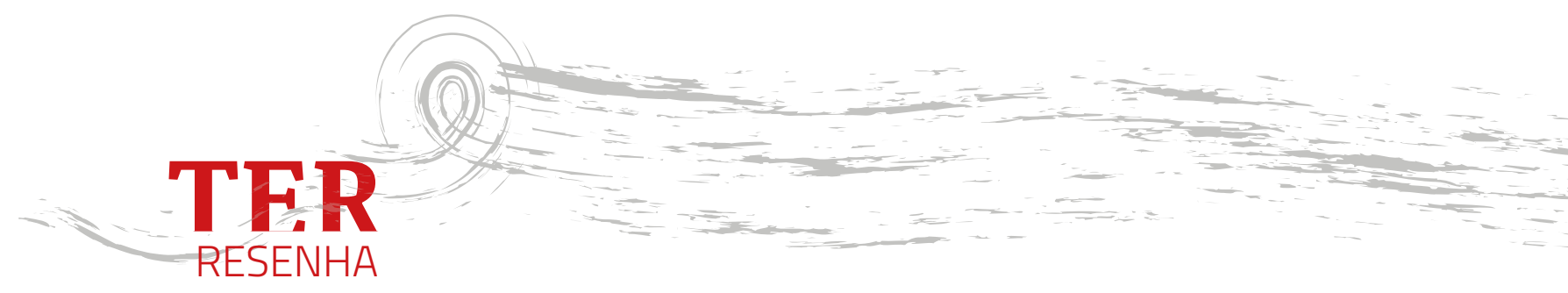

Universidade Federal de São

RODRIGO FRARE BARONI

Paulo, Guarulhos, Brasil

\title{
BOGART DUPLO DE BOGART: PISTAS DA PERSONA CINEMATOGRÁFICA DE HUMPHREY BOGART, 1941-1946
}

Luís Felipe Sobral. 2015. Bogart Duplo de Bogart: pistas da persona cinematográfica de Humphrey Bogart, 1941-1946. São Paulo, Terceiro Nome, 152p.
No livro, Bogart duplo de Bogart, Luís Felipe Sobral centraliza sua análise na construção da persona cinematográfica de Humphrey Bogart, ator hollywoodiano que iniciou sua carreira no teatro e em papéis secundários feitos por ele nos filmes de gângsteres da década de 1930, mas que ficou conhecido por seus papéis de protagonista de filmes de detetive na década de 1940.

0 autor seleciona três filmes-chave para compor sua análise ao longo dos capítulos do livro, são eles: O falcão maltês (1941), Casablanca (1942), A beira do abismo (1946). Ao abordar as cenas do filme, Sobral também escrutina textos da época, estabelece, materiais publicitários, relações entre filmes do mesmo período, entre outros materiais, na tentativa de evitar uma transposição de sua própria leitura para os filmes e, ao descrever as cenas, se esforça para tentar se aproximar da "cultura visual" do período de produção dos filmes. Esse movimento de análise lembra algumas preocupações em relação ao anacronismo expostas pelo historiador Lucien Febvre em O problema da incredulidade no século XVI (2009), na medida em que Febvre, preocupado com a forma com que Rabelais era lido no século XVI, tenta evitar ao máximo o anacronismo em um exercício de tentar se apropriar das categorias de percepção deste período. Há, portanto, entre estes dois autores, um esforço em sentido semelhante. 
Sobral nos conta que toma como inspiração o conceito de "tecnologia do gênero', elaborado por Teresa Lauretis a partir dos trabalhos de Michel Foucault sobre a sexualidade" (Sobral 2015, 20). Segundo essa concepção, a ideia de gênero poderia ser pensada como produto de tecnologias sociais tais como o cinema. Porém, Sobral marca uma diferença entre a análise que empreende em seu livro e o modelo de análise de Lauretis, já que: enquanto esta ressalta os elementos internos das produções que analisa, Sobral diz explicitamente que o foco de sua análise não é tanto os elementos internos dos filmes, mas sim o movimento entre o que aparece nos filmes e o contexto de sua produção.

Dessa maneira a análise feita por Sobral segue um duplo movimento: pensar o "visível da imagem" e o "invisível de sua produção" (Ibid., 20), ou seja, aquilo que é visto pelo espectador nos filmes estrelados por Bogart (e que se inserem no que o autor chama de uma "cultura visual") ${ }^{1}$ e aquilo que não está presente nestas imagens, mas que são condição de sua produção. Nesse sentido, busca-se compreender a trajetória de Bogart e as relações estabelecidas pelo ator no contexto de produção cinematográfico hollywoodiano (a fim de inserir o ator e sua persona cinematográfica, os quais Sobral faz questão de diferenciar) dentro de seu contexto histórico, político, econômico e social (em uma análise marcada pela influência do pensamento bourdieusiano) ${ }^{2}$. Dessa forma o autor articula (em termos econômicos, políticos e sociais) as imagens produzidas e a "autonomia relativa" de Bogart na construção de sua própria persona.

O prefácio escrito por Heloisa Pontes traz, além de uma descrição sobre os procedimentos e métodos analíticos de sobral, uma breve mas instigante comparação entre as figuras de Humphrey Bogart e Jon Hamm (ator que fez o papel do personagem Don Drapper na série Mad Men), comparação esta que renderia estudos promissores sobre como estes dois atores e seus personagens constroem ideais e padrões de masculinidade no cinema. Porém a análise de Sobral, apesar de partir da preocupação com a ideia de gênero, concentra seus esforços na tentativa de compreensão do como a formação da persona cinematográfica serve como mediador entre ator e personagem e que por vezes acaba por confundi-los, ou uni-los, como se fossem uma única e mesma entidade. Na formação da persona residiria uma especificidade do cinema que, para Sobral, ao contrário do teatro, torna inescapável a evidência de traços físicos do ator, e na medida em que os filmes são reproduzíveis, por diversas vezes, acabam por estabelecer uma relação mais duradoura entre o ator e seus personagens. Cabe dizer que essas diferenciações entre o cinema e o teatro são trazidas pelo

1. Conceito que Sobral deriva do que "Michael Baxandall denominou 'estilo cognitivo do período"' $(2015,54)$.

2. Ver Bourdieu (2015). 
autor em diversos momentos do livro e se fazem importantes para compreender a biografia e trajetória de Bogart uma vez que ele passa pelas duas formas expressivas ao longo de sua vida.

Se a formação da persona cinematográfica é o articulador entre vida e corpo do ator e o papel do personagem que este interpreta, é precisamente aí que reside o potencial analítico de tal categoria para Sobral, visto que o conceito passa então a colocar em relação o corpo do ator as suas relações sociais, políticas e econômicas, a influência (ou autonomia-relativa) que o mesmo possui no processo de produção cinematográfico, sua inserção no contexto mais amplo de produção do cinema hollywoodiano e mundial e os contextos históricos dessas produções, bem como as próprias narrativas fílmicas. Todas essas características influenciariam na construção da persona, e, ao mesmo tempo, aparecem articuladas por ela. Esses elementos formam e são lidos, para o autor, nas imagens cinematográficas do período.

Consideremos a seguinte passagem:

A característica mais notável desse material publicitário reside no fato de que as figuras em cena não são apenas personagens nem seus respectivos interpretes, e, sim, as próprias personas dos artistas. Tal processo resume-se em retomar um conjunto de atributos associados a um personagem de um filme anterior e vinculá-lo ao personagem do filme promovido; a continuidade é preservada, pois um só artista interpreta ambos; no entanto, não se trata apenas de um ou outro personagem, tampouco do próprio artista, porém de sua persona, que só assume uma forma concreta ao inscrever, por meio da performance, o primeiro no corpo do segundo (Ibid., 224).

Essa passagem nos mostra, de maneira sintética, o modo pelo qual Sobral articula essas problemáticas a partir do conceito de persona, o qual não devemos tomar como uma forma estática definida a priori. A maneira com que se delineia a construção do conceito (e da própria persona de Bogart) no livro é dinâmica, tal como os diversos momentos da vida de Bogart. Ao mesmo tempo, podemos inverter esse movimento para pensar como a construção da persona do ator teria contribuído para com as produções hollywoodianas e para formação de corpos e modos de ser e estar no mundo. Podemos fazer esta última afirmação à medida em que notamos que Sobral articula o conceito de persona à duas formulações trabalhadas por Marcel Mauss (2003): a noção de "pessoa" e o conceito de "técnicas corporais". Sobral faz questão de nos lembrar que Mauss já havia notado o papel do cinema na educação e propagação de diferentes técnicas corporais que, por sua vez, mediam nossa relação com o mundo. 
Os personagens e as imagens do filme se associam, carregam vestígios (por assim dizer) da trajetória e dos processos de sua formação, e eles se encontram de alguma maneira inscritos no corpo do ator. o corpo possui assim uma dimensão bastante importante no ensaio e muitas vezes se encontra na posição de um vértice articulador das relações. Além disso, garante, como vimos na citação acima, uma espécie de continuidade a qual confere certas expectativas ao público em relação ao que se verá na tela, o que, para Sobral, faz parte também de uma espécie de modus operandi da indústria cinematográfica hollywoodiana que, a partir de determinado momento, passa a se pautar por modelos de filmes que fazem sucesso para o grande público e que encontrava na seleção dos atores (que por sua vez eram associados aos personagens que já haviam interpretado) mais ou menos adequados dentro de cada um desses modelos.

É bastante interessante observar como Sobral estabelece a relação entre o contexto histórico-social do período, as ações do governo americano sobre o cinema hollywoodiano e a reverberação destes elementos nas produções cinematográficas, e, consequentemente, no delineamento da persona de Bogart tal como nas relações em que seu personagem estabelece com as mulheres pelas quais se apaixona (nos filmes evidentemente) e em como as tensões amorosas se resolveram no interior da trama dada a conjuntura do momento. A análise que Sobral faz nesse ensaio é muito bem trabalhada nos termos do "visível" da imagem (ainda que não seja o eixo central da análise) e do "invisível" de sua produção (este sim foco das preocupações). E nesse sentido, durante o livro, o autor ocupa-se mais em mostrar como se opera a construção de imagens e valores através da indústria cinematográfica hollywoodiana, do que com o momento da recepção dessas construções cinematográficas e em que medida elas afetam o corpo dos espectadores. Mesmo assim, o livro escrito por Sobral abre um campo de possibilidades com múltiplas entradas possíveis para pensar o papel do cinema e da construção da persona cinematográfica na formação e transformação de nossas ideias sobre gênero e sexualidade, como aquela apontada por Heloisa Pontes.

\section{REFERÊNCIAS BIBLIOGRÁFICAS}

Bourdieu, Pierre. 2015. A distinção: crítica social do julgamento, $2^{\text {a }}$ Edição, Porto Alegre: Zouk Mauss, Marcel. 2003. Sociologia e antropologia. São Paulo: Cosac Naify.

Febvre, Lucien. 2009. O problema da incredulidade no século XVI: a religião de Rabelais. São Paulo: Companhia das Letras. 
Sobral, Luís Felipe. 2015. Bogart duplo de Bogart: pistas da persona cinematográfica de Humphrey Bogart, 1941-1946. São Paulo: Terceiro Nome.

recebido

06.07.2017

aprovado

05.09.2017
RODRIGO FRARE BARONI

Aluno do Programa de Pós-graduação em Ciências Sociais da UNIFESP

(mestrado) e membro do Grupo de Pesquisas Visuais e Urbanas (VISURB). 